\title{
Microglial Polarization: Novel Therapeutic Strategy against Ischemic Stroke
}

\author{
Yimeng Xue ${ }^{1,2, \#}$, Ding Nie ${ }^{1, \#}$, Lin-Jian Wang, ${ }^{1,2}$ Han-Cheng Qiu${ }^{1}$, Long Ma ${ }^{1}$, Ming-Xin Dong ${ }^{3}$, \\ Wen-Jun Tu ${ }^{1,3 *}$, Jizong Zhao ${ }^{1,2,4,5,6^{*}}$
}

\begin{abstract}
${ }^{1}$ Department of Neurosurgery, Beijing Tiantan Hospital, Capital Medical University, Beijing, China. ${ }^{2}$ Savaid Medical School, University of Chinese Academy of Sciences, Beijing, China. ${ }^{3}$ Institute of Radiation Medicine, Chinese Academy of Medical Science \& Peking Union Medical College, Tianjin, China. ${ }^{4}$ China National Clinical Research Center for Neurological Diseases, Beijing, China. ${ }^{5}$ Center of Stroke, Beijing Institute for Brain Disorders, Beijing, China. ${ }^{6}$ Beijing Key Laboratory of Translational Medicine for Cerebrovascular Disease, Beijing, China

[Received March 14, 2020; Revised June 28, 2020; Accepted July 1, 2020]

ABSTRACT: Ischemic stroke, which is the second highest cause of death and the leading cause of disability, represents $\sim 71 \%$ of all strokes globally. Some studies have found that the key elements of the pathobiology of stroke is immunity and inflammation. Microglia are the first line of defense in the nervous system. After stroke, the activated microglia become a double-edged sword, with distinct phenotypic changes to the deleterious M1 types and neuroprotective M2 types. Therefore, ways to promote microglial polarization toward M2 phenotype after stroke have become the focus of attention in recent years. In this review, we discuss the process of microglial polarization, summarize the alternation of signaling pathways and epigenetic regulation that control microglial polarization in ischemic stroke, aiming to find the potential mechanisms by which microglia can be transformed into the M2 polarized phenotype.
\end{abstract}

Key words: microglia, cell polarization, ischemic stroke, mechanism, treatment

\section{Introduction}

Stroke is the second leading cause of death and the highest disabling disease in the world, with an increasing incidence in developing countries [1-3]. China suffers the greatest burden of stroke globally, with about 2.4 million new cases and 1.1 million stroke-related deaths annually [4]. Ischemic stroke induced by arterial occlusion is the major cause of strokes and account for $\sim 71 \%$ of all strokes in the world. The standard treatment for acute ischemic stroke is intravenous thrombolysis with tissue-type plasminogen activator (t-PA) and endovascular treatment which are time-critical [5]. A nationwide populationbased study reported that only approximately $20 \%$ of stroke patients received thrombolytic therapy within 3 hours in China [6]. Therefore, it is urgently needed to establish other potential therapies.

Immunity and inflammation play an important role in the pathophysiology of stroke [7]. Being the key innate immune cells, microglia act as guardians responding to various acute brain injuries, including ischemic stroke[8, 9]. As the resident macrophages of the central nervous system (CNS), the morphology and gene expression of microglia change while responding to brain injury, such is

*Correspondence should be addressed to: Dr. Wen-Jun Tu (Email: tuwenjun@irm-cams.ac.cn) and Dr. Jizong Zhao (Email: zhaojz205@163.com), Beijing Tiantan Hospital, Capital Medical University, Beijing, China. "these authors contributed equally to this work.

Copyright: () 2020 Xue Y et al. This is an open-access article distributed under the terms of the Creative Commons Attribution License, which permits unrestricted use, distribution, and reproduction in any medium, provided the original author and source are credited. 
called microglial activation [10]. Activated microglia is one of the most important cellular components of poststroke neuroinflammation, which occurs within an hour to more than a month, developing four morphological states: ramified, intermediate, amoeboid and round [11-13]. Age is a critical co-factor for CNS diseases. Interestingly, the function of microglial cells changed with aging and the morphology of the microglia is more de-ramified [14]. Compared with young microglial cells, aged microglia activation is amplified and prolonged [15]. The existence of an aging-related microglial phenotype in the aged human brain is verified and it is involved in pathological processes of CNS diseases [16].

Microglia could present different phenotypes in accordance with the stimulus, the environment, and the period, which is called microglial polarization [17, 18]. Similar to macrophages, microglial polarization is divided into classically activated (M1, pro-inflammatory) phenotype and alternatively activated (M2, antiinflammatory) phenotype. Many differences of the polarization of these two cell types have been noted [19].
Polarized microglia differ from polarized macrophages in protein expression, phagocytosis, and injury response. In response to inflammatory factor, M2 microglia are more protective and tend to maintain the M2 phenotype status [20]. The phenotype of microglial cells also changed with aging. Aged microglia demonstrated a propensity for the development of a pro-inflammatory phenotype with increased pro-inflammatory cytokines and inflammatory receptors, which is referred to as primed, reactive or sensitized [15]. Microglia play an important role in various neurological diseases, involving in multiple aspects of neuroinflammation, such as cytotoxicity, repair, immunosuppression and regeneration at the basis of different polarization states [21]. Thus, we make a review to discuss the process of microglial polarization and summarize the alternation of signaling pathways and epigenetic modifications that control microglial polarization in ischemic stroke, aiming to find the potential mechanisms and drugs by which microglia can be shifted from M1 into the M2 polarized type after ischemic stroke.

Table 1. Characteristics of M1 and M2 microglia.

\begin{tabular}{|c|c|c|c|c|}
\hline & Stimulus & Phenotypic markers & Substances produce & Function \\
\hline M1 & IFN- $\gamma$, LPS & $\begin{array}{l}\text { iNOS, TNF- } \alpha, \text { MHCII, } \\
\text { CD86 }\end{array}$ & $\begin{array}{l}\text { IL-23, IL-18, IL-12, } \\
\text { IL-1 } \beta, \text { IL-6, TNF- } \alpha \text {, NO, } \\
\text { CCL2, CXCL10, ROS, } \\
\text { MMP9, MMP3 }\end{array}$ & $\begin{array}{l}\text { Proinflammatory, Phagocytosis, } \\
\text { Cytotoxicity, Present antigens, } \\
\text { Kill intracellular pathogens }\end{array}$ \\
\hline M2a & IL-4, IL-13 & $\begin{array}{l}\text { Arg-1, Fizz-1, } \\
\text { Chitinase3-like 3, } \\
\text { Chemokines } \\
\text { IGF-1, CD206, }\end{array}$ & Extracellular matrix proteins & $\begin{array}{l}\text { Tissue repair; Remodeling of } \\
\text { extracellular matrix; Phagocytosis }\end{array}$ \\
\hline M2b & $\begin{array}{l}\text { Immune } \\
\text { complex, } \\
\text { TLRs agonists }\end{array}$ & $\begin{array}{l}\text { IL-10, Cyclooxyge- } \\
\text { nase } 2 \text {, Sphingosine } \\
\text { kinase, suppressor of } \\
\text { cytokine signaling } 3\end{array}$ & IL-1 $\beta$, IL-6, IL-10, TNF-a & $\begin{array}{l}\text { Phagocytosis } \\
\text { Removal of tissue debris }\end{array}$ \\
\hline M2c & $\begin{array}{l}\text { IL-10, TGF- } \beta \text {, } \\
\text { glucocorticoid }\end{array}$ & CD163 & IL-10, TGF- $\beta$ & $\begin{array}{l}\text { Anti-inflammatory } \\
\text { Phagocytosis }\end{array}$ \\
\hline
\end{tabular}

\section{Microglial Polarization}

Microglia act as a 'double-edged sword' in the CNS by representing neurotoxic or neuroprotective functions according to phenotypic polarization [22]. M1 polarized microglia secrete inflammatory cytokines that lead to tissue damage. In contrast, M2 microglia have a neuroprotective effect by producing anti-inflammatory cytokines, inhibiting nerve injury, and promoting tissue repair [23]. M1 microglia are characterized by its amoeboid shape, high mobility, producing various proinflammatory cytokines. Interferon $\gamma$ (IFN $\gamma$ ) secreted by $\mathrm{T}$ helper 1 cells activates signal transducer and activator of transcription 1 (STAT1) factor through Janus kinase (JAK)1/JAK2 signaling, inducing M1 microglia to produce pro-inflammatory cytokines [24]. Another pathway is activited by lipopolysaccharide (LPS) or damage-associated molecular pattern (DAMP) stimulation accompanied with Toll-like receptor 4 (TLR4) $[25,26]$. Along with producing various proinflammatory cytokines (IL-23, IL-18, IL-12, IL-1 $\beta$, IL6 , TNF- $\alpha$, CCL2, and CXCL10), ROS, NO, and proteolytic enzymes matrix metalloproteinase-9 (MMP9) and matrix metalloproteinase-3(MMP3) [27-30], M1 microglia serve as antigen presentation to avoid pathogens invasion [31].

Alternatively, activated M2 microglia are composed of three subtypes with unique markers and biological function: M2a, M2b and M2c [32]. With the stimulation of IL-4, IL-13, M2a microglia display enhanced 
expression of Arginase-1, Ym1, Insulin-Like growth Factor-1 (IGF-1), CD206, chitinase 3-like 3 and found in the inflammatory zone1 (Fizz1) [33, 34], mainly contributing to cell regeneration. Induced by immune complexes and TLRs agonists, M2b phenotype produce increased expression of IL- $1 \beta$, CD86, suppressor of cytokine signaling 3 (SOCS3), IL-1 $\beta$, IL-6, IL-10, involving in phagocytosis and removal of tissue debris $[35,36]$. When the response of inflammatory shows weakened, transforming growth factor $\beta$ (TGF- $\beta$ ), IL-10, and glucocorticoids induce M2c phenotype to help tissue regeneration [37] (see Table 1).

In response to an immune challenge, the process of microglial polarization shift towards priming with aging [38]. Under the stimulation of LPS, aged microglia showed hyperactive response with higher induction of inflammatory IL-1 and anti-inflammatory IL-10. And aged microglia prolonged the downregulation of the fractalkine receptor and failed to up-regulation of IL-4 receptor[39]. Taken together, the ability of microglia to lower inflammation in the brain is impaired. The understanding of the aged microglia phenotype and function in humans is limited, particularly in the process of microglial polarization. Mounting evidence is needed to confirm the role of aged microglia polarization in ischemia stroke.

\section{Microglial Polarization in Neurological Disorders}

Although it is oversimplified to divide microglia into the M1 and M2 phenotypes, the classification has important implications for comprehending the role of microglia in
CNS diseases [40]. The role of microglial polarization in a variety of neurological disorders has been illuminated. Targeting M2 phenotype polarization has been proved to be a potential therapeutic strategy. In Alzheimer's disease (AD), studies have shown that the dysfunction of M2 microglia and the excessive activation of M1 microglia promote inflammatory pathological injury. Through polarization moderation, microglia could induce tissue repair and phagocytosis to reduce $A \beta$ levels, alleviating $\mathrm{AD}$ pathological damage [22]. In $\mathrm{AD}$ mouse models, DSP-8658 and Bexarotene have proved to enhance microglial A $\beta$ phagocytosis[41, 42]. In Parkinson's disease (PD), the dopaminergic degeneration is involved in microglial polarization, Rosiglitazone boosts the M2 phenotype over the pro-inflammatory phenotype modulating microglia polarization [43]. Although the pathology of amyotrophic lateral sclerosis (ALS) has still not been completely understood [44], hirsutella sinensis prolongs the lifespan of ALS mice by promoting transition of microglial polarization from M1 to M2 phenotype[45]. In Huntington's disease, microglial polarization affects striatal neuronal dysfunction [46]. In multiple sclerosis (MS), M1 microglia have a greater ability to present antigens, leading to demyelination and neurodegeneration, while M2 microglia protect oligodendrocytes and neurons from damage and ameliorate disease severity[26]. A recent clinical trial showed that anti-pathogenic human endogenous retrovirus type W (pHERVW) envelope protein (ENV)mediated microglial polarization exerts neuroprotective effects in MS[47] (see Table 2).

Table 2. Summary of microglial polarization in neurological disorders.

\begin{tabular}{|c|c|c|c|}
\hline Neurological disorders & The function of polarized microglia & Model & Drugs $(\mathrm{M} 2 \rightarrow \mathrm{M} 1)$ \\
\hline Alzheimer's disease (AD) & $\begin{array}{l}\text { M1 phenotypic inhibits } A \beta \text { clearance, while } \\
\text { M2 phenotypic enhances } A \beta \text { clearance. }\end{array}$ & $\begin{array}{l}\text { Mouse } \\
\text { model }\end{array}$ & $\begin{array}{l}\text { DSP-8658 } \\
\text { Bexarotene }\end{array}$ \\
\hline Parkinson's disease (PD) & $\begin{array}{l}\text { Dopaminergic degeneration is associated } \\
\text { with microglial polarization. }\end{array}$ & $\begin{array}{l}\text { Mouse } \\
\text { model }\end{array}$ & Rosiglitazone \\
\hline $\begin{array}{l}\text { Amyotrophic lateral } \\
\text { sclerosis (ALS) }\end{array}$ & $\begin{array}{l}\text { Elimination of apoptotic cells, production of } \\
\text { growth factors, maintenance of synapse } \\
\text { structure and function are the main function } \\
\text { of microglia. }\end{array}$ & $\begin{array}{l}\text { Mouse } \\
\text { model }\end{array}$ & $\begin{array}{l}\text { Minocycline } \\
\text { Rho kinase } \\
\text { inhibitor[114] } \\
\text { Hirsutella sinensis }\end{array}$ \\
\hline Huntington's disease (HD) & $\begin{array}{l}\text { Microglial polarization affects striatal } \\
\text { neuronal dysfunction. }\end{array}$ & $\begin{array}{l}\text { Mouse } \\
\text { model }\end{array}$ & Minocycline \\
\hline Multiple Sclerosis (MS) & $\begin{array}{l}\text { M1 microglia have a greater antigen } \\
\text { presenting ability, leading to demyelination } \\
\text { and neurodegeneration. While M2 microglia } \\
\text { protect oligodendrocytes and neurons from } \\
\text { damage and ameliorate disease severity. }\end{array}$ & $\begin{array}{l}\text { Clinical } \\
\text { phase } \\
\text { IIb }\end{array}$ & $\begin{array}{l}\text { Anti-pathogenic } \\
\text { human endogenous } \\
\text { retrovirus type W } \\
\text { envelope protein } \\
\text { (pHERV-W ENV) }\end{array}$ \\
\hline Neurological disorders & The function of polarized microglia & Model & Drugs $(\mathrm{M} 2 \rightarrow \mathrm{M} 1)$ \\
\hline
\end{tabular}




\section{Polarized Microglia-based Therapy in Ischemic Stroke}

While ischemic stroke occurs, the microenvironment of microglia has changed and classic (M1) or alternative (M2) microglia are polarized responding to peripheral inflammation. At the early stage of ischemic stroke, microglia tend to assume the M2 phenotype responding to acute injury, and then microglia transform into the M1 phenotype that induces an inflammatory response [48]. The mechanism of microglial polarization during ischemic stroke involves multiple pathways that have not been entirely clear. Present studies showed that the type of microglial polarization was decided by signaling pathways. Understanding the accurate mechanism of microglial polarization, we can find a breakthrough in the treatment. In the following, we discuss the transcription factors and epigenetic regulation associated with ischemia-induced microglial polarization to find out the mechanism of microglial M1 to M2 transition (see Table $3)$.

Table 3. Studies of polarized microglia-based therapy in ischemic stroke.

\begin{tabular}{|c|c|c|c|c|}
\hline Drug/agent & Model & Mechanism & Effect & Reference \\
\hline TWS119 & MCAO mice & $\begin{array}{l}\text { Wnt } / \beta \text {-catenin } \\
\text { pathway } \\
\text { activator }\end{array}$ & $\begin{array}{l}\text { Modulate microglia to anti-inflammatory } \\
\text { phenotype }\end{array}$ & [115] \\
\hline Melatonin & $\begin{array}{l}\text { MCAO mice } \\
\text { BV2 microglia }\end{array}$ & $\begin{array}{l}\text { STAT3 } \\
\text { pathway } \\
\text { activator }\end{array}$ & $\begin{array}{l}\text { Decrease expression of pro-inflammatory } \\
\text { markers and increased expression of anti- } \\
\text { inflammatory markers }\end{array}$ & [116] \\
\hline HAMI3379 & Rat & $\begin{array}{l}\text { CysLTR } \\
\text { antagonist } \\
\text { NF-אB } \\
\text { pathway }\end{array}$ & $\begin{array}{l}\text { Inhibit microglia } \mathrm{M} 1 \text { polarization and promote } \\
\text { microglia polarization toward } \mathrm{M} 2 \text { phenotype }\end{array}$ & {$[117]$} \\
\hline$\beta$-caryophyllene (BCP) & $\begin{array}{l}\text { MCAO } \\
\text { Mice }\end{array}$ & $\begin{array}{l}\text { TLR4 } \\
\text { pathway } \\
\text { antagonist }\end{array}$ & $\begin{array}{l}\text { Decrease the secretion of pro-inflammatory } \\
\text { cytokines (IL-1 } \beta \text {, TNF- } \alpha \text { ) and polarize } \\
\text { microglia towards the M2 phenotype }\end{array}$ & {$[118]$} \\
\hline $\begin{array}{l}\text { Suberoylanilide } \\
\text { hydroxamic acid }\end{array}$ & MCAO mouse & $\begin{array}{l}\text { Histone } \\
\text { deacetylase } \\
\text { inhibitors }\end{array}$ & $\begin{array}{l}\text { Suppresse M1 cytokine expression (IL- } 6 \text {, } \\
\text { TNF- } \alpha \text {, and iNOS) while promoted the } \\
\text { transcription of M } 2 \text { cytokines (Arg- } 1 \text { and IL- } \\
\text { 10) }\end{array}$ & [119] \\
\hline $\begin{array}{l}\text { Isosteviol Sodium (STV- } \\
\mathrm{Na})\end{array}$ & $\begin{array}{l}\text { MCAO mouse } \\
\text { BV2 microglia }\end{array}$ & $\operatorname{miR}-146 a-5 p$ & $\begin{array}{l}\text { Promote M2 polarization and inhibit M1 } \\
\text { response }\end{array}$ & {$[120]$} \\
\hline Baicalein & MCAO rat & $\begin{array}{l}\mathrm{NF}-\kappa \mathrm{B} \\
\text { antagonist }\end{array}$ & $\begin{array}{l}\text { Reduced expression of the M1 marker (CD } 16 \\
\text { and CD86), and increase expression of the M2 } \\
\text { marker, (CD } 163 \text { and CD206) }\end{array}$ & [121] \\
\hline Berberine & MCAO mice & $\begin{array}{l}\text { AMPK } \\
\text { activator }\end{array}$ & $\begin{array}{l}\text { Inhibit M1 polarization and promote M2 } \\
\text { polarization }\end{array}$ & {$[122]$} \\
\hline CKLF1 & MCAO mice & $\begin{array}{l}\mathrm{NF}-\kappa \mathrm{B} \\
\text { activator }\end{array}$ & $\begin{array}{l}\text { Modulated primary microglia skew toward } \\
\text { M1 phenotype }\end{array}$ & {$[123]$} \\
\hline $\begin{array}{l}\text { Exosomes from LPS- } \\
\text { stimulated macrophages }\end{array}$ & Rat & & $\begin{array}{l}\text { Skew the microglial functional polarity from } \\
\text { M1 toward an anti-inflammatory M2 } \\
\text { phenotype. }\end{array}$ & {$[124]$} \\
\hline $\begin{array}{l}\text { Nicotinamide } \\
\text { phosphoribosyltransferase } \\
\text { (NAMPT) }\end{array}$ & MCAO mice & & $\begin{array}{l}\text { Inhibite pro-inflammatory microglia, } \\
\text { promoted microglia polarization toward the } \\
\text { anti-inflammatory phenotype, }\end{array}$ & {$[125]$} \\
\hline Propagermanium & MCAO mice & $\begin{array}{l}\text { CCR2 } \\
\text { inhibitor }\end{array}$ & $\begin{array}{l}\text { Inhibite inflammatory cytokines releasing, } \\
\text { such as TNF- } \alpha \text {, IFN- } \gamma \text {, IL-1 } \beta \text {, IL-6, IL-12, IL- } \\
17 \text {, and IL-23, inhibite CD16 expressed in } \\
\text { microglia. }\end{array}$ & [126] \\
\hline Glycine & $\begin{array}{l}\text { SpragueDawley } \\
\text { rats BV-2 cells }\end{array}$ & $\begin{array}{l}\text { NF-kB p } 65 \\
\text { inhibitor }\end{array}$ & Inhibite M1 microglial polarization & [127] \\
\hline Xuesaitong & MCAO mice & $\begin{array}{l}\text { STAT3 } \\
\text { inhibitor }\end{array}$ & $\begin{array}{l}\text { Promote the polarization of microglia to an } \\
\text { M2 phenotype }\end{array}$ & {$[128]$} \\
\hline $\begin{array}{l}\text { Sphingosine 1-phosphate } \\
\text { receptor } \\
\text { subtype } 3(\mathrm{~S} 1 \mathrm{P})\end{array}$ & MCAO mice & $\begin{array}{l}\text { MAPK and } \\
\text { Akt } \\
\text { activator }\end{array}$ & $\begin{array}{l}\text { Involve its modulation of microglial activation } \\
\text { and M1 polarization }\end{array}$ & [129] \\
\hline L-3-n-Butylphthalide & MCAO mice & & $\begin{array}{l}\text { Skewing M1 microglia polarization towards } \\
\text { M2 }\end{array}$ & {$[130]$} \\
\hline
\end{tabular}




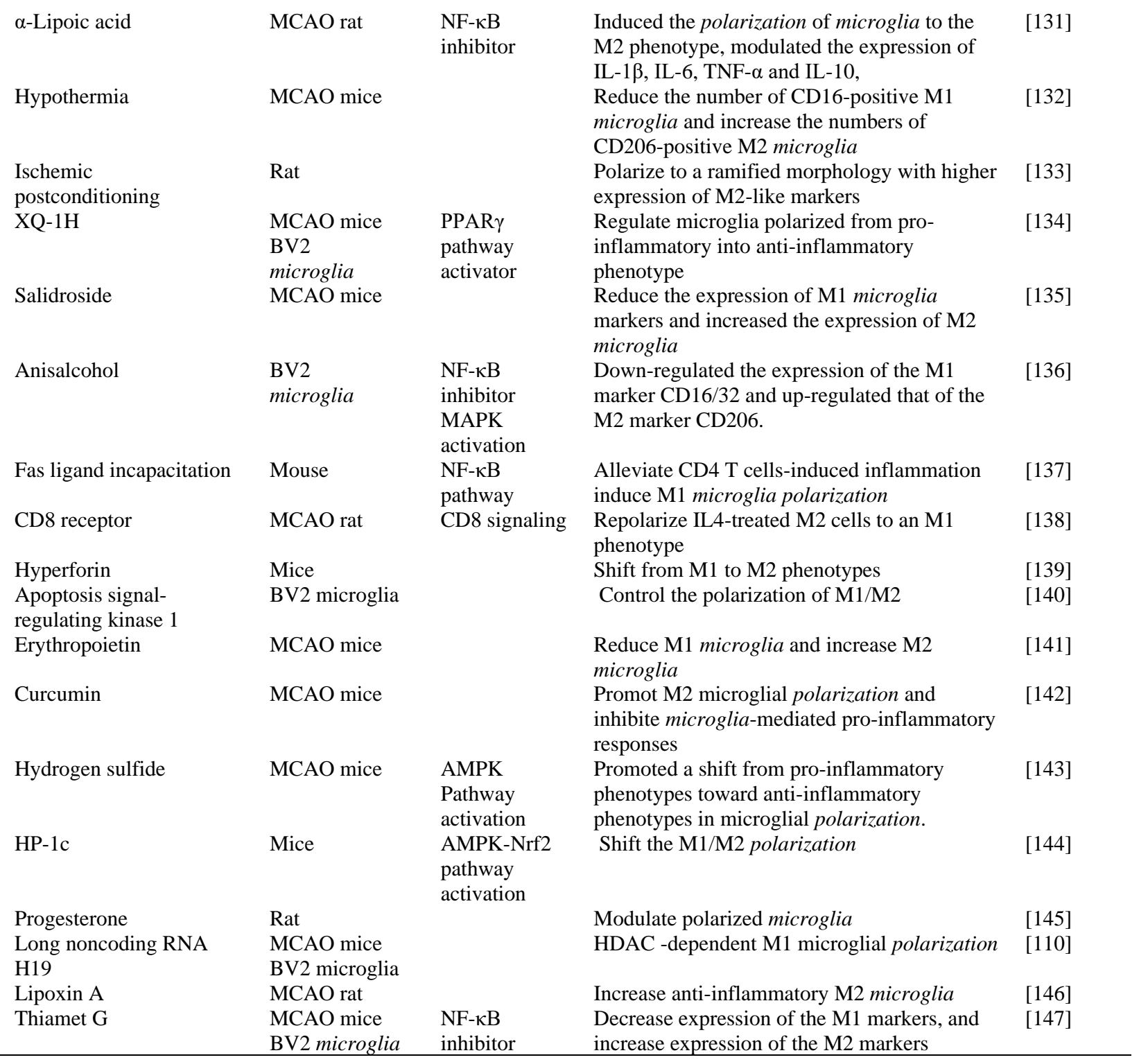

\subsection{Transcription Factor}

Two important transcription factors, c-AMP response element binding protein (CREB) and nuclear factor- $\mathrm{\kappa B}$ $(\mathrm{NF}-\kappa \mathrm{B})$, are involved in the mechanism of microglial polarization[49]. NF- $\kappa B$ is a traditional transcription factor activated by LPS and expressed in many cell types in the nervous system $[50,51]$. There are five members of the NF- $\kappa \mathrm{B}$ family, including NF- $\kappa \mathrm{B} 1$ (p50), NF- $\kappa \mathrm{B} 2$ (p52), RelA (p65), RelB and c-Rel. More pieces of evidence suggest that NF- $\kappa \mathrm{B}$ signaling plays an important role in inflammatory diseases and has biphasic functions in ischemic stroke [51-53]. NF- $\mathrm{KB}$ signal pathway is related to the expression of M1 phenotype genes (IL-1, IL-2, IL-6, IL-12, TNF- $\alpha$, inducible nitric oxide synthase (iNOS), and cyclooxygenase-2 (COX-2)), playing a detrimental role in ischemic stroke[50, 54]. The expression of matrix metalloproteinases (MMPs) is mediated by NF- $\mathrm{KB}$ signaling, leading to blood brain barrier damage and brain inflammatory cell infiltration [55, 56]. CD147 (cluster of differentiation 147) could induce extracellular MMP, being a promising therapeutic target for ischemic stroke [56]. In contrast, NF- $\mathrm{BB}$ p50 is a key redox signaling mechanism regulating the M1/M2 balance in microglia. NF- $\mathrm{BB}$ p50 homodimers could play a negative role in STAT1 activity and M1 phenotype gene transcription, increasing M2 polarized mediators (Arg-1, Ym1 and Fizz1) [57]. Lower NF- $\kappa B$ p65 expression has potential protective effect by promoting M2 phenotype microglial polarization and alleviating inflammation[58]. Other transcription factors may regulate microglial polarization by influencing the activity of NF- $\kappa \mathrm{B}$. Notch signaling promote production of IFN- $\gamma$ through recruitment of p50 and c-Rel, in response to LPS. With 
NF- $\mathrm{BB}$ activation, inflammation and neurotoxicity exacerbate ischemic brain damage [59]. The crosstalk between Notch and NF- $\mathrm{BB}$ inhibits the expression of $\operatorname{PPAR} \gamma$ which is necessary for the induction of the M2 phenotype [60, 61]. STAT1 and STAT3 are able to increase the expression of NF- $\kappa \mathrm{B}$ p65. Inhibiting the activation of STAT1 and STAT3 prevents the inflammatory reaction caused by brain ischemia, thereby reducing the occurrence of infarction and edema.

In contrast, $\mathrm{CREB}$ cooperated with $\mathrm{C} / \mathrm{EBP} \beta$ promote tissue repair by amplification of M2-specific gene [62]. Confoundingly, the expression of M1-specific genes associated with inflammation is also affected by C/EBP $\beta$ [63]. The role of $\mathrm{C} / \mathrm{EBP} \beta$ in regulating microglial phenotypes depends on the competitiveness of CREB and NF- $\kappa B$ [64]. CREB-binding protein (CBP) is another competition site. The increase of CREB activity has a negative effect on the combination of CBP and NF- $\kappa B$ $[65,66]$. With the activation of TLRs, interferon regulatory factor-3 (IRF-3) is phosphorylated and interacts with CBP promoting the M2 polarization. The RelA/CBP/p300 complex is formed at the same time [6769]. In summary, the balance of NF- $\kappa B$ and CREB plays a crucial role in the microglial polarization in cerebral ischemia [49].

In addition, nuclear factor erythroid 2-related factor 2 (Nrf2) is activated and involved in the anti-inflammatory effect of the M2 phenotype microglia, which is a key factor of brain endogenous defense system, in response to oxidative stress [70, 71]. After the activation of Nrf2, neuro-inflammation induced by LPS was inhibited both in vivo and in vitro [72, 73]. A study concluded that achyranthes bidentata polypeptidek's could inhibit neuroinflammation in BV2 microglia through Nrf2 dependent mechanism[74]. Through the activation of the Nrf2 pathway and the inhibition of the NF- $\mathrm{kB}$ pathway, Biochanin A may contribute to the neuro-protection against ischemic injury in rats by anti-oxidative and antiinflammatory actions [75]. Other studies conclude that the disruption of mTORC1 pathway could shift microglial phenotype to decrease brain inflammation [76].

\subsection{Epigenetic Modifications}

Besides the transcription factors above, the polarization and functional status of microglia require precise regulation of target gene expression, which can be achieved by epigenetic modifications. Epigenetics refers to modifications that do not alter the genetic code but control how information is encoded in DNA in a tissueand context-specific manner developmentally or environmentally [77]. The mechanisms of epigenetic modifications are usually mediated by modifications of histones and other chromatin proteins (such as methylation, acetylation, and phosphorylation), methylation of CpG DNA motifs, hydroxymethylation, and non-coding RNA [78, 79]. The epigenetic markers histone modification and miRNA involved in microglial polarization and activation processes are reportedly more than the others [80]. The following summarizes the recent findings on the role of epigenetic modifications regulating microglial polarization.

\subsubsection{MiRNA}

MicroRNAs (miRNAs) are small non-coding RNA molecules that regulate gene expression posttranscriptionally. MiRNAs repress gene expression by combining with the 3'-untranslated region, coding sequence, or 5'UTR of target genes [81, 82]. A total of $30 \%-90 \%$ of human genes are regulated by miRNAs that modulate cell growth, activation, and differentiation [83]. M1- and M2-polarized microglia exhibit distinct miRNA profiles. Recent research has also defined a role for miRNA in microglial polarization [84]. With the development of miRNA research, more and more miRNAs are related to microglial polarization phenotypes.

It is well accepted that miRNA-155 expression promotes M1 polarization by suppressing M2-signature genes and that miRNA-124 enhances the M2 phenotype by targeting M1 genes [85-87]. In MACO mice, miR-124 proved to increase the survival of neuron and M2 microglial polarization [81]. In IL-4 stimulated microglia, miR-145 was the most increased miRNA, facilitating the M2 phenotype in microglia[88]. Overexpression of miR146a contributed to polarization transitions from M1 to M2 phenotype in microglia [89]. Isosteviol sodium can downregulate miRNA-181b to protect mouse brain with ischemia stroke by repressing NF- $\mathrm{KB}$ signaling pathways, providing a novel therapy for ischemic stroke [90]. MiRNA-128 could reduce the M1 phenotypic markers and increase the M2 phenotypic markers, promoting the viability of microglia [91]. Overall, targeting proinflammatory or anti-inflammatory miRNAs to regulate the microglial polarization provides new direction in the treatment of ischemic stroke. However, further studies are badly in need to clarify the function of miRNAs in the switch of microglial phenotype. Additionally, how to deliver miRNAs to the central nervous system (CNS) through the blood brain barrier (BBB) and prevent the degradation of miRNAs are also unsolved. With mechanisms of microglial polarization unveiled, targeting specific miRNAs may provide major restorative therapies and microglial polarization-based therapy will be potential future research field of the treatment of ischemia stroke [92]. 


\subsubsection{DNA Methylation}

DNA methylation is an epigenetic process catalyzed by DNA methyltransferases (DNMTs). Methyl groups are added to DNA nucleotides, which leads to chromatin condensation and alteration of gene expression [93]. DNMT maintains cytosine methylation through mitotic and meiotic cell divisions and is widely expressed in brain tissue. The whole DNA methylation in brain is upregulated after cerebral ischemia, which may control gene expression profile in cerebral ischemia injury [94, 95]. Aberrant DNA methylation patterns have been proved in cerebral ischemia. Reduced DNA methylation play a neuroprotective role in ischemic stroke. Inhibition of DNMT1 expression affects chromatin structure and increases expression and combination of transcription factors (such as hypoxia-inducible factor-1 (HIF-1)) with neuroprotective genes [96, 97]. It has been reported that there is an intrinsic link between DNA methylation in microglia and aging-mediated cognitive deficits [98]. However, the role of DNA methylation has remained to be further elucidated in microglial polarization in ischemic stroke. DNA methylation is a modifiable regulation and it is possible that in the future methylated or unmethylated genes could be a drug target for stroke treatment.

\subsubsection{Histone Modifications}

The electrostatic interaction of positive charges on histones and negative charges on DNA inhibits tightly packed chromatin structures[96]. The acetylation of histones on lysine residues can neutralize the positive charge, thereby disrupting the stability of the histoneDNA interaction, and subsequently changing the concentrated chromatin into an open, loosely packed chromatin structure, allowing gene recruitment activators or inhibitors of transcription and it can be reversed by histone deacetylases (HDACs) activity [99, 100]. It has been reported that HDAC inhibitors (HDACi) have antiinflammatory effects in neuroprotection [101]. The protection of HDACi on microglia polarization is involved in its anti-inflammatory effect in the early phase of cerebral ischemia, reducing the activation of microglia and promote activated microglia to protective phenotype, providing a promising therapeutic intervention [102, 103]. It has been reported that the inhibition of HDAC1 and HDAC2 activity after transient cerebral ischemia promotes microglia polarization towards M2 Phenotype[104]. Valproic acid treatment attenuated the inflammatory response by modulating microglia polarization through STAT1-mediated acetylation of the NF- $\kappa B$ pathway, dependent of HDAC3 activity [105]. Enhancer of zeste homolog-2 (EZH2), a histone methyltransferase, has been recognized to promote M1 microglial polarization but repress M2 microglial polarization probably via activating STAT3[106]. On the contrary, histone 3 lysine 27 (H3K27) demethylase Jumonji d3 (Jmjd3) promotes M2 microglial polarization but represses M1 microglia polarization [107, 108]. Dehydroepiandrosterone (DHEA) is the most abundant circulating steroid hormone in humans, TrkA signaling activated by DHEA is an effective regulator of inflammation through Jmjd3-dependent pathway, providing potential treatments for neuroinflammatory diseases (Fig. 1) [109].

Besides above, there are other epigenetic regulations contributing to the polarization of microglia in the ischemic stroke. Long noncoding RNA H19 promotes neuroinflammation by driving HDAC1-dependent M1 microglial polarization, suggesting a novel H19-based diagnosis and therapy for ischemic stroke [110]. MiR30d-5p- enhanced adipose-derived stem cells (ADSC) derived exosomes prevent cerebral injury by inhibiting microglial polarization to M1 [111]. Investigation of epigenetic regulation of microglia polarization and function is at an early stage and there are many unknown areas for future research. Finally, recent breakthroughs have opened a new door to epigenetic therapy of ischemic stroke.

More and more evidence has revealed that modulators of microglial phenotypes may be a promising therapeutic approach for the treatment of ischemic stroke. However, fundamental differences of the cellular environment and damage-response between macrophages and microglia exist, the M1/M2 oversimple classification may not be applicable to microglia. Unbiased methods such as genome-wide transcriptomics, epigenomics and proteomics are urgent needed to aid research progress [112].

Comprehensive single-cell RNA analysis of CNS immune cells identified disease-associated microglia (DAM), which is a kind of microglia with specifically transcription and function. The emergence of DAM may provide a new explanation for the contradictory views on the detrimental or beneficial effects of microglia in recent years [113].

\section{Conclusion}

In cerebral ischemia, the neuroprotective effects of M2polarized microglia cells include clearing debris as well as promoting tissue repair. Increasing evidence indicates that shifting microglial phenotype from the proinflammatory M1 state toward the anti-inflammatory M2 phenotype may be an effective therapeutic strategy for ischemic stroke. Importantly, several signalling pathways - such as NF- $\mathrm{kB}$, and Wnt/ $\beta$-catenin - may be 
critically involved in microglial polarization in ischemic stroke. The underlying mechanisms of microglial polarization in ischemic stroke are still not well understood and need to be further elucidated.

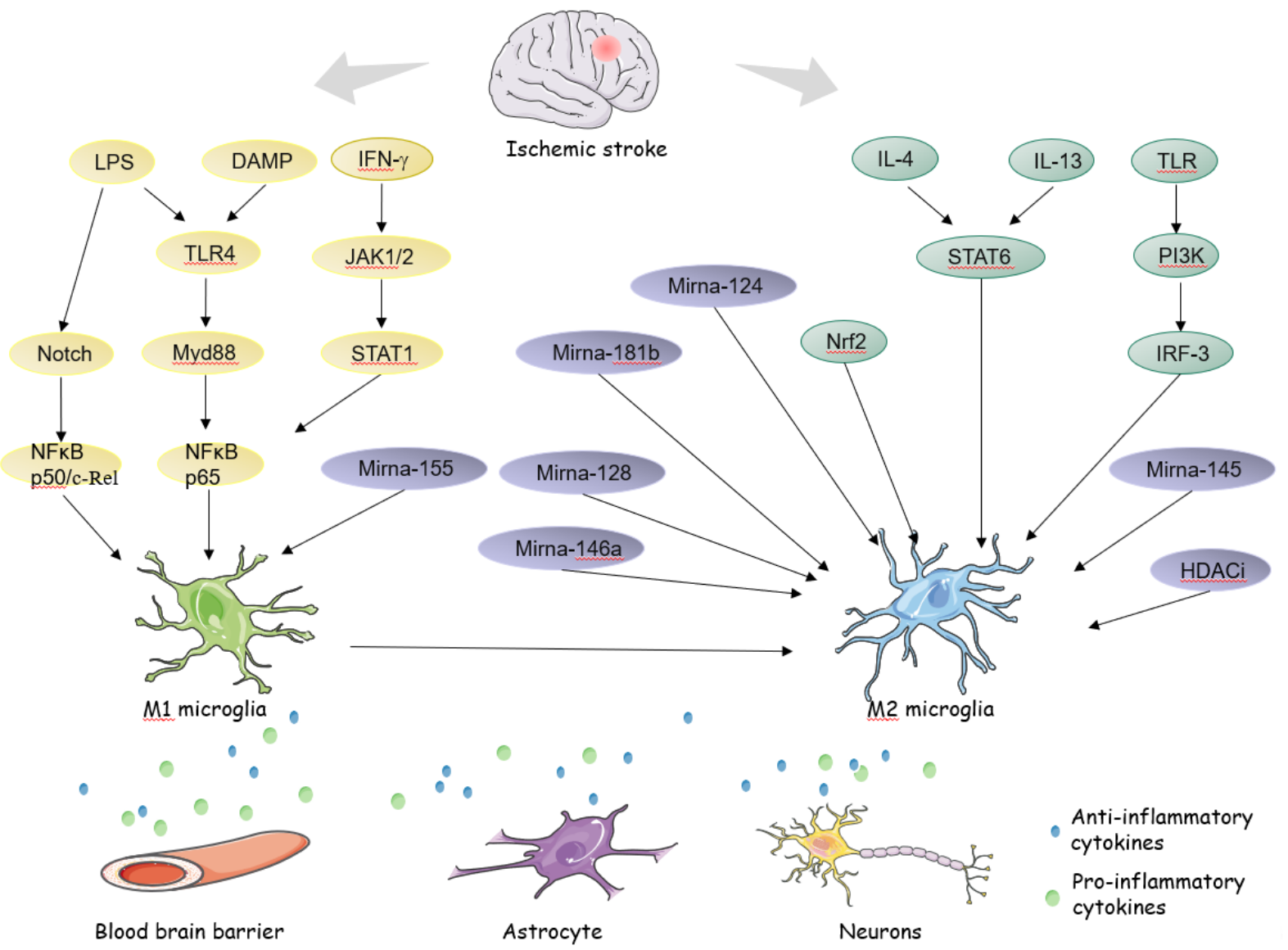

Figure 1. Microglia polarization after ischemic stroke. M1 microglia produce pro-inflammatory cytokines to exacerbate neural death, astrocyte apoptosis, and blood brain barrier (BBB) disruption. Conversely, M2 microglia produce anti-inflammatory cytokines to maintain BBB integrity, promote the proliferation and differentiation of neural cells and tissue repair.

\section{Acknowledgements}

This study was supported by grants from " $13^{\text {th }}$ Five-Year Plan" National Science and Technology Supporting Plan (2015BAI12B04), Beijing Science and Technology Supporting PlanD16110000381605 and the Beijing Municipal Administration of Hospitals' Mission Plan (SML20150501); CAMS Innovation Fund for Medical Science (No.2017-I2M-1-016 and 2019-I2M-2-006); Natural Science Foundation of Tianjin (No. 19JCYBJC26600); China Postdoctoral Science Foundation funded project (No. 2019M660921); Science Foundation for Post Doctorate Research of the Beijing (No.2017-ZZ-123).

\section{Conflict of interest}

All authors have no conflicts of interest to disclose.

\section{References}

[1] Campbell BCV, De Silva DA, Macleod MR, Coutts SB, Schwamm LH, Davis SM, et al. (2019). Ischaemic stroke. Nat Rev Dis Primers, 5:70.

[2] (2019). Global, regional, and national burden of neurological disorders, 1990-2016: a systematic analysis for the Global Burden of Disease Study 2016. Lancet Neurol, 18:459-480.

[3] Shen Y, Chao BH, Cao L, Tu WJ, Wang LD (2020). Stroke Center Care and Outcome: Results from the CSPPC Stroke Program. Transl Stroke Res, 11:377386.

[4] Wang W, Jiang B, Sun H, Ru X, Sun D, Wang L, et al. (2017). Prevalence, Incidence, and Mortality of Stroke in China: Results from a Nationwide Population-Based Survey of 480687 Adults. Circulation, 135:759-771. 
[5] Zerna C, Thomalla G, Campbell BCV, Rha J-H, Hill MD (2018). Current practice and future directions in the diagnosis and acute treatment of ischaemic stroke. Lancet, 392:1247-1256.

[6] Wang Y, Liao X, Zhao X, Wang DZ, Wang C, Nguyen-Huynh MN, et al. (2011). Using recombinant tissue plasminogen activator to treat acute ischemic stroke in China: analysis of the results from the Chinese National Stroke Registry (CNSR). Stroke, 42:1658-1664.

[7] Iadecola C, Anrather J (2011). The immunology of stroke: from mechanisms to translation. Nat Med, 17:796-808.

[8] Lan X, Liu R, Sun L, Zhang T, Du G (2011). Methyl salicylate 2-O- $\beta$-D-lactoside, a novel salicylic acid analogue, acts as an anti-inflammatory agent on microglia and astrocytes. J Neuroinflammation, 8:98.

[9] Moskowitz MA, Lo EH, Iadecola C (2010). The science of stroke: mechanisms in search of treatments. Neuron, 67:181-198.

[10] Kettenmann H, Hanisch UK, Noda M, Verkhratsky A (2011). Physiology of microglia. Physiol Rev, 91:461553.

[11] Davalos D, Grutzendler J, Yang G, Kim JV, Zuo Y, Jung S, et al. (2005). ATP mediates rapid microglial response to local brain injury in vivo. Nat Neurosci, 8:752-758.

[12] Thiel A, Heiss WD (2011). Imaging of microglia activation in stroke. Stroke, 42:507-512.

[13] Thored P, Heldmann U, Gomes-Leal W, Gisler R, Darsalia V, Taneera J, et al. (2009). Long-term accumulation of microglia with proneurogenic phenotype concomitant with persistent neurogenesis in adult subventricular zone after stroke. Glia, 57:835849.

[14] von Bernhardi R, Tichauer J, Eugenín-von Bernhardi L (2011). Proliferating culture of aged microglia for the study of neurodegenerative diseases. J Neurosci Methods, 202:65-69.

[15] Norden DM, Godbout JP (2013). Review: microglia of the aged brain: primed to be activated and resistant to regulation. Neuropathol Appl Neurobiol, 39:19-34.

[16] Olah M, Patrick E, Villani AC, Xu J, White CC, Ryan $\mathrm{KJ}$, et al. (2018). A transcriptomic atlas of aged human microglia. Nat Commun, 9:539.

[17] Biswas SK, Mantovani A (2010). Macrophage plasticity and interaction with lymphocyte subsets: cancer as a paradigm. Nat Immunol, 11:889-896.

[18] Girard S, Brough D, Lopez-Castejon G, Giles J, Rothwell NJ, Allan SM (2013). Microglia and macrophages differentially modulate cell death after brain injury caused by oxygen-glucose deprivation in organotypic brain slices. Glia, 61:813-824.

[19] Ginhoux F, Greter M, Leboeuf M, Nandi S, See P, Gokhan S, et al. (2010). Fate mapping analysis reveals that adult microglia derive from primitive macrophages. Science, 330:841-845.

[20] Durafourt BA, Moore CS, Zammit DA, Johnson TA, Zaguia F, Guiot MC, et al. (2012). Comparison of polarization properties of human adult microglia and blood-derived macrophages. Glia, 60:717-727.

[21] Chhor V, Le Charpentier T, Lebon S, Oré MV, Celador IL, Josserand J, et al. (2013). Characterization of phenotype markers and neuronotoxic potential of polarised primary microglia in vitro. Brain Behav Immun, 32:70-85.

[22] Yao K, Zu HB (2020). Microglial polarization: novel therapeutic mechanism against Alzheimer's disease. Inflammopharmacology, 28:95-110.

Benarroch EE (2013). Microglia: Multiple roles in surveillance, circuit shaping, and response to injury. Neurology, 81:1079-1088.

Hu X, Li P, Guo Y, Wang H, Leak RK, Chen S, et al. (2012). Microglia/macrophage polarization dynamics reveal novel mechanism of injury expansion after focal cerebral ischemia. Stroke, 43:3063-3070.

Kigerl KA, Gensel JC, Ankeny DP, Alexander JK, Donnelly DJ, Popovich PG (2009). Identification of two distinct macrophage subsets with divergent effects causing either neurotoxicity or regeneration in the injured mouse spinal cord. J Neurosci, 29:1343513444.

Cao L, He C (2013). Polarization of macrophages and microglia in inflammatory demyelination. Neurosci Bull, 29:189-198.

[27] Boche D, Perry VH, Nicoll JA (2013). Review: activation patterns of microglia and their identification in the human brain. Neuropathol Appl Neurobiol, 39:3-18.

[28] Connolly C, Magnusson-Lind A, Lu G, Wagner PK, Southwell AL, Hayden MR, et al. (2016). Enhanced immune response to MMP3 stimulation in microglia expressing mutant huntingtin. Neuroscience, 325:7488.

[29] Zhao Y, Wei ZZ, Lee JH, Gu X, Sun J, Dix TA, et al. (2020). Pharmacological hypothermia induced neurovascular protection after severe stroke of transient middle cerebral artery occlusion in mice. Exp Neurol, 325:113133.

[30] Liu CY, Wang X, Liu C, Zhang HL (2019). Pharmacological Targeting of Microglial Activation: New Therapeutic Approach. Front Cell Neurosci, 13:514.

[31] Cherry JD, Olschowka JA, O'Banion MK (2014). Neuroinflammation and M2 microglia: the good, the bad, and the inflamed. J Neuroinflammation, 11:98. Latta CH, Sudduth TL, Weekman EM, Brothers HM, Abner EL, Popa GJ, et al. (2015). Determining the role of IL-4 induced neuroinflammation in microglial activity and amyloid- $\beta$ using BV2 microglial cells and APP/PS1 transgenic mice. J Neuroinflammation, 12:41.

[33] Ma Y, Wang J, Wang Y, Yang GY (2017). The biphasic function of microglia in ischemic stroke. Prog Neurobiol, 157:247-272.

[34] Mecha M, Feliú A, Carrillo-Salinas FJ, RuedaZubiaurre A, Ortega-Gutiérrez S, de Sola RG, et al. (2015). Endocannabinoids drive the acquisition of an 
alternative phenotype in microglia. Brain Behav Immun, 49:233-245.

[35] Lan X, Han X, Li Q, Yang QW, Wang J (2017). Modulators of microglial activation and polarization after intracerebral haemorrhage. Nat Rev Neurol, 13:420-433.

[36] Franco R, Fernández-Suárez D (2015). Alternatively activated microglia and macrophages in the central nervous system. Prog Neurobiol, 131:65-86.

[37] Mantovani A, Sica A, Sozzani S, Allavena P, Vecchi A, Locati M (2004). The chemokine system in diverse forms of macrophage activation and polarization. Trends Immunol, 25:677-686.

[38] Wynne AM, Henry CJ, Huang Y, Cleland A, Godbout JP (2010). Protracted downregulation of CX3CR1 on microglia of aged mice after lipopolysaccharide challenge. Brain Behav Immun, 24:1190-1201.

[39] Henry CJ, Huang Y, Wynne AM, Godbout JP (2009). Peripheral lipopolysaccharide (LPS) challenge promotes microglial hyperactivity in aged mice that is associated with exaggerated induction of both proinflammatory IL-1beta and anti-inflammatory IL-10 cytokines. Brain Behav Immun, 23:309-317.

[40] Hu X, Leak RK, Shi Y, Suenaga J, Gao Y, Zheng P, et al. (2015). Microglial and macrophage polarizationnew prospects for brain repair. Nat Rev Neurol, 11:5664.

[41] Yamanaka M, Ishikawa T, Griep A, Axt D, Kummer MP, Heneka MT (2012). PPAR $\gamma /$ RXR $\alpha$-induced and CD36-mediated microglial amyloid- $\beta$ phagocytosis results in cognitive improvement in amyloid precursor protein/presenilin 1 mice. J Neurosci, 32:1732117331.

[42] Landreth GE, Cramer PE, Lakner MM, Cirrito JR, Wesson DW, Brunden KR, et al. (2013). Response to comments on "ApoE-directed therapeutics rapidly clear $\beta$-amyloid and reverse deficits in AD mouse models". Science, 340:924-g.

[43] Pisanu A, Lecca D, Mulas G, Wardas J, Simbula G, Spiga S, et al. (2014). Dynamic changes in pro- and anti-inflammatory cytokines in microglia after PPAR$\gamma$ agonist neuroprotective treatment in the MPTPp mouse model of progressive Parkinson's disease. Neurobiol Dis, 71:280-291.

[44] Kim BW, Koppula S, Kumar H, Park JY, Kim IW, More SV, et al. (2015). $\alpha$-Asarone attenuates microglia-mediated neuroinflammation by inhibiting NF kappa B activation and mitigates MPTP-induced behavioral deficits in a mouse model of Parkinson's disease. Neuropharmacology, 97:46-57.

[45] Shang HY, Zhang JJ, Fu ZF, Liu YF, Li S, Chen S, et al. (2020). Therapeutic effects of hirsutella sinensis on the disease onset and progression of amyotrophic lateral sclerosis in SOD1 transgenic mouse model. CNS Neurosci Ther, 26:90-100.

[46] Tai YF, Pavese N, Gerhard A, Tabrizi SJ, Barker RA, Brooks DJ, et al. (2007). Microglial activation in presymptomatic Huntington's disease gene carriers. Brain, 130:1759-1766.
Kremer D, Gruchot J, Weyers V, Oldemeier L, Göttle P, Healy L, et al. (2019). pHERV-W envelope protein fuels microglial cell-dependent damage of myelinated axons in multiple sclerosis. Proc Natl Acad Sci U S A, 116:15216-15225.

[48] Perego C, Fumagalli S, De Simoni MG (2011). Temporal pattern of expression and colocalization of microglia/macrophage phenotype markers following brain ischemic injury in mice. J Neuroinflammation, $8: 174$.

[49] Wang J, Xing H, Wan L, Jiang X, Wang C, Wu Y (2018). Treatment targets for M2 microglia polarization in ischemic stroke. Biomed Pharmacother, 105:518-525.

[50] Taetzsch T, Levesque S, McGraw C, Brookins S, Luqa $\mathrm{R}$, Bonini MG, et al. (2015). Redox regulation of NF$\kappa \mathrm{B}$ p50 and $\mathrm{M} 1$ polarization in microglia. Glia, 63:423-440.

[51] Schneider A, Martin-Villalba A, Weih F, Vogel J, Wirth T, Schwaninger M (1999). NF-kappaB is activated and promotes cell death in focal cerebral ischemia. Nat Med, 5:554-559.

[52] DiDonato JA, Mercurio F, Karin M (2012). NF- $\mathrm{BB}$ and the link between inflammation and cancer. Immunol Rev, 246:379-400.

[53] Barrat FJ, Crow MK, Ivashkiv LB (2019). Interferon target-gene expression and epigenomic signatures in health and disease. Nat Immunol, 20:1574-1583.

[54] Liang Y, Zhou Y, Shen P (2004). NF-kappaB and its regulation on the immune system. Cell Mol Immunol, 1:343-350.

[55] Lenglet S, Montecucco F, Mach F (2015). Role of matrix metalloproteinases in animal models of ischemic stroke. Curr Vasc Pharmacol, 13:161-166.

[56] Jin R, Xiao AY, Chen R, Granger DN, Li G (2017). Inhibition of CD147 (Cluster of Differentiation 147) Ameliorates Acute Ischemic Stroke in Mice by Reducing Thromboinflammation. Stroke, 48:33563365.

[57] Porta C, Rimoldi M, Raes G, Brys L, Ghezzi P, Di Liberto D, et al. (2009). Tolerance and M2 (alternative) macrophage polarization are related processes orchestrated by p50 nuclear factor kappaB. Proc Natl Acad Sci U S A, 106:14978-14983.

[58] Yao X, Liu S, Ding W, Yue P, Jiang Q, Zhao M, et al. (2017). TLR4 signal ablation attenuated neurological deficits by regulating microglial M1/M2 phenotype after traumatic brain injury in mice. J Neuroimmunol, 310:38-45.

[59] Liu HC, Zheng MH, Du YL, Wang L, Kuang F, Qin HY, et al. (2012). N9 microglial cells polarized by LPS and IL4 show differential responses to secondary environmental stimuli. Cell Immunol, 278:84-90.

[60] Herwig MC, Bergstrom C, Wells JR, Höller T, Grossniklaus HE (2013). M2/M1 ratio of tumor associated macrophages and PPAR-gamma expression in uveal melanomas with class 1 and class 2 molecular profiles. Exp Eye Res, 107:52-58.

[61] Arumugam TV, Cheng YL, Choi Y, Choi YH, Yang $\mathrm{S}$, Yun YK, et al. (2011). Evidence that gamma- 
secretase-mediated Notch signaling induces neuronal cell death via the nuclear factor-kappaB-Bcl-2interacting mediator of cell death pathway in ischemic stroke. Mol Pharmacol, 80:23-31.

[62] Ruffell D, Mourkioti F, Gambardella A, Kirstetter P, Lopez RG, Rosenthal N, et al. (2009). A CREB$\mathrm{C} / \mathrm{EBPbeta}$ cascade induces M2 macrophage-specific gene expression and promotes muscle injury repair. Proc Natl Acad Sci U S A, 106:17475-17480.

[63] Gorgoni B, Maritano D, Marthyn P, Righi M, Poli V (2002). C/EBP beta gene inactivation causes both impaired and enhanced gene expression and inverse regulation of IL-12 p40 and p35 mRNAs in macrophages. J Immunol, 168:4055-4062.

[64] Ma J, Liu C, Yang Y, Yu J, Yang J, Yu S, et al. (2018). $\mathrm{C} / \mathrm{EBP} \beta$ Acts Upstream of NF- $\kappa \mathrm{B}$ P65 Subunit in OxLDL-Induced IL-1 $\beta$ Production by Macrophages. Cell Physiol Biochem, 48:1605-1615.

[65] Bi X, Jiang B, Zhou J, Luo L, Yin Z (2019). Phosphorylated Hsp27 prevents LPS-induced excessive inflammation in THP-1 cells via suppressing ROS-mediated upregulation of CBP. Cell Biol Int.

[66] Martin M, Rehani K, Jope RS, Michalek SM (2005). Toll-like receptor-mediated cytokine production is differentially regulated by glycogen synthase kinase 3 . Nat Immunol, 6:777-784.

[67] Qin BY, Liu C, Srinath H, Lam SS, Correia JJ, Derynck R, et al. (2005). Crystal structure of IRF-3 in complex with CBP. Structure, 13:1269-1277.

[68] Guo XJ, Tian XS, Ruan Z, Chen YT, Wu L, Gong Q, et al. (2014). Dysregulation of neurotrophic and inflammatory systems accompanied by decreased CREB signaling in ischemic rat retina. Exp Eye Res, 125:156-163.

[69] Mukherjee SP, Behar M, Birnbaum HA, Hoffmann A, Wright PE, Ghosh G (2013). Analysis of the RelA:CBP/p300 interaction reveals its involvement in NF-кB-driven transcription. PLoS Biol, 11:e1001647.

[70] Shah SA, Khan M, Jo MH, Jo MG, Amin FU, Kim MO (2017). Melatonin Stimulates the SIRT1/Nrf2 Signaling Pathway Counteracting Lipopolysaccharide (LPS)-Induced Oxidative Stress to Rescue Postnatal Rat Brain. CNS Neurosci Ther, 23:33-44.

[71] Zheng Y, Zhu G, He J, Wang G, Li D, Zhang F (2019). Icariin targets $\mathrm{Nrf} 2$ signaling to inhibit microgliamediated neuroinflammation. Int Immunopharmacol, 73:304-311.

[72] Liu S, Li G, Tang H, Pan R, Wang H, Jin F, et al. (2019). Madecassoside ameliorates lipopolysaccharide-induced neurotoxicity in rats by activating the Nrf2-HO-1 pathway. Neurosci Lett, 709:134386.

[73] Bahar E, Kim JY, Yoon H (2017). Quercetin Attenuates Manganese-Induced Neuroinflammation by Alleviating Oxidative Stress through Regulation of Apoptosis, iNOS/NF- $\kappa \mathrm{B}$ and $\mathrm{HO}-1 / \mathrm{Nrf} 2$ Pathways. Int J Mol Sci, 18.

[74] Cheng Q, Shen Y, Cheng Z, Shao Q, Wang C, Sun H, et al. (2019). Achyranthes bidentata polypeptide $\mathrm{k}$ suppresses neuroinflammation in BV2 microglia through Nrf2-dependent mechanism. Ann Transl Med, 7:575.

[75] Guo M, Lu H, Qin J, Qu S, Wang W, Guo Y, et al. (2019). Biochanin A Provides Neuroprotection Against Cerebral Ischemia/Reperfusion Injury by Nrf2-Mediated Inhibition of Oxidative Stress and Inflammation Signaling Pathway in Rats. Med Sci Monit, 25:8975-8983.

[76] Li D, Wang C, Yao Y, Chen L, Liu G, Zhang R, et al. (2016). mTORC1 pathway disruption ameliorates brain inflammation following stroke via a shift in microglia phenotype from M1 type to M2 type. FASEB J, 30:3388-3399.

[77] Natoli G (2010). Maintaining cell identity through global control of genomic organization. Immunity, 33:12-24.

[78] Sadakierska-Chudy A, Filip M (2015). A comprehensive view of the epigenetic landscape. Part II: Histone post-translational modification, nucleosome level, and chromatin regulation by ncRNAs. Neurotox Res, 27:172-197.

[79] Van den Bossche J, Neele AE, Hoeksema MA, de Winther MP (2014). Macrophage polarization: the epigenetic point of view. Curr Opin Lipidol, 25:367373.

[80] Das Gupta K, Shakespear MR, Iyer A, Fairlie DP, Sweet MJ (2016). Histone deacetylases in monocyte/macrophage development, activation and metabolism: refining HDAC targets for inflammatory and infectious diseases. Clin Transl Immunology, 5:e62.

[81] Hamzei Taj S, Kho W, Riou A, Wiedermann D, Hoehn M (2016). MiRNA-124 induces neuroprotection and functional improvement after focal cerebral ischemia. Biomaterials, 91:151-165.

[82] Fang Z, Rajewsky N (2011). The impact of miRNA target sites in coding sequences and in 3'UTRs. PloS one, 6:e18067.

[83] Veremeyko T, Siddiqui S, Sotnikov I, Yung A, Ponomarev ED (2013). IL-4/IL-13-dependent and independent expression of miR-124 and its contribution to M2 phenotype of monocytic cells in normal conditions and during allergic inflammation. PloS one, 8:e81774.

[84] Graff JW, Dickson AM, Clay G, McCaffrey AP, Wilson ME (2012). Identifying functional microRNAs in macrophages with polarized phenotypes. J Biol Chem, 287:21816-21825.

[85] Moore CS, Rao VT, Durafourt BA, Bedell BJ, Ludwin SK, Bar-Or A, et al. (2013). miR-155 as a multiple sclerosis-relevant regulator of myeloid cell polarization. Ann Neurol, 74:709-720.

[86] Cai X, Yin Y, Li N, Zhu D, Zhang J, Zhang CY, et al. (2012). Re-polarization of tumor-associated macrophages to pro-inflammatory M1 macrophages by microRNA-155. J Mol Cell Biol, 4:341-343.

[87] Ponomarev ED, Veremeyko T, Barteneva N, Krichevsky AM, Weiner HL (2011). MicroRNA-124 promotes microglia quiescence and suppresses EAE 
by deactivating macrophages via the C/EBP- $\alpha$-PU.1 pathway. Nat Med, 17:64-70.

[88] Liu X, Liu J, Zhao S, Zhang H, Cai W, Cai M, et al. (2016). Interleukin-4 Is Essential for Microglia/Macrophage M2 Polarization and LongTerm Recovery After Cerebral Ischemia. Stroke, 47:498-504.

[89] Huang Y, Liao Z, Lin X, Wu X, Chen X, Bai X, et al. (2019). Overexpression of miR-146a Might Regulate Polarization Transitions of BV-2 Cells Induced by High Glucose and Glucose Fluctuations. Front Endocrinol (Lausanne), 10:719.

[90] Zhang H, Zhong K, Lu M, Mei Y, Tan E, Sun X, et al. (2018). Neuroprotective effects of isosteviol sodium through increasing CYLD by the downregulation of miRNA-181b. Brain Res Bull, 140:392-401.

[91] Yang Z, Xu J, Zhu R, Liu L (2017). Down-Regulation of miRNA-128 Contributes to Neuropathic Pain Following Spinal Cord Injury via Activation of P38. Med Sci Monit, 23:405-411.

[92] Guo Y, Hong W, Wang X, Zhang P, Körner H, Tu J, et al. (2019). MicroRNAs in Microglia: How do MicroRNAs Affect Activation, Inflammation, Polarization of Microglia and Mediate the Interaction Between Microglia and Glioma? Front Mol Neurosci, 12:125.

[93] Robertson KD (2005). DNA methylation and human disease. Nat Rev Genet, 6:597-610.

[94] Krupinski J, Carrera C, Muiño E, Torres N, AlBaradie R, Cullell N, et al. (2018). DNA Methylation in Stroke. Update of Latest Advances. Comput Struct Biotechnol J, 16:1-5.

[95] Endres M, Meisel A, Biniszkiewicz D, Namura S, Prass K, Ruscher K, et al. (2000). DNA methyltransferase contributes to delayed ischemic brain injury. J Neurosci, 20:3175-3181.

[96] Tang J, Zhuang S (2019). Histone acetylation and DNA methylation in ischemia/reperfusion injury. Clin Sci (Lond), 133:597-609.

[97] Jhelum P, Karisetty BC, Kumar A, Chakravarty S (2017). Implications of Epigenetic Mechanisms and their Targets in Cerebral Ischemia Models. Curr Neuropharmacol, 15:815-830.

[98] Matt SM, Lawson MA, Johnson RW (2016). Aging and peripheral lipopolysaccharide can modulate epigenetic regulators and decrease IL-1 $\beta$ promoter DNA methylation in microglia. Neurobiol Aging, 47:1-9.

[99] Shogren-Knaak M, Ishii H, Sun JM, Pazin MJ, Davie JR, Peterson CL (2006). Histone H4-K16 acetylation controls chromatin structure and protein interactions. Science, 311:844-847.

[100] Tessarz P, Kouzarides T (2014). Histone core modifications regulating nucleosome structure and dynamics. Nature reviews. Nat Rev Mol Cell Biol, 15:703-708.

[101] Park MJ, Sohrabji F (2016). The histone deacetylase inhibitor, sodium butyrate, exhibits neuroprotective effects for ischemic stroke in middle-aged female rats. J Neuroinflammation, 13:300.
[102] Wang G, Shi Y, Jiang X, Leak RK, Hu X, Wu Y, et al. (2015). HDAC inhibition prevents white matter injury by modulating microglia/macrophage polarization through the GSK3 $3 /$ PTEN/Akt axis. Proc Natl Acad Sci U S A, 112:2853-2858.

[103] Ji J, Wang J, Yang J, Wang XP, Huang JJ, Xue TF, et al. (2019). The Intra-nuclear SphK2-S1P Axis Facilitates M1-to-M2 Shift of Microglia via Suppressing HDAC1-Mediated KLF4 Deacetylation. Front Immunol, 10:1241.

[104] Han Z, Zhao H, Tao Z, Wang R, Fan Z, Luo Y, et al. (2018). TOPK Promotes Microglia/Macrophage Polarization towards M2 Phenotype via Inhibition of HDAC1 and HDAC2 Activity after Transient Cerebral Ischemia. Aging Dis, 9:235-248.

[105] Chen S, Ye J, Chen X, Shi J, Wu W, Lin W, et al. (2018). Valproic acid attenuates traumatic spinal cord injury-induced inflammation via STAT1 and NF-кB pathway dependent of HDAC3. J Neuroinflammation, 15:150.

[106] Chen J, Zhang M, Zhang X, Fan L, Liu P, Yu L, et al. (2019). EZH2 inhibitor DZNep modulates microglial activation and protects against ischaemic brain injury after experimental stroke. Eur J Pharmacol, 857:172452.

[107] Das A, Arifuzzaman S, Yoon T, Kim SH, Chai JC, Lee YS, et al. (2017). RNA sequencing reveals resistance of TLR4 ligand-activated microglial cells to inflammation mediated by the selective jumonji H3K27 demethylase inhibitor. Sci Rep, 7:6554.

[108] Tang Y, Li T, Li J, Yang J, Liu H, Zhang XJ, et al. (2014). Jmjd3 is essential for the epigenetic modulation of microglia phenotypes in the immune pathogenesis of Parkinson's disease. Cell Death Differ, 21:369-380.

[109] Alexaki VI, Fodelianaki G, Neuwirth A, Mund C, Kourgiantaki A, Ieronimaki E, et al. (2018). DHEA inhibits acute microglia-mediated inflammation through activation of the TrkA-Akt1/2-CREB-Jmjd3 pathway. Mol Psychiatry, 23:1410-1420.

[110] Wang J, Zhao H, Fan Z, Li G, Ma Q, Tao Z, et al. (2017). Long Noncoding RNA H19 Promotes Neuroinflammation in Ischemic Stroke by Driving Histone Deacetylase 1-Dependent M1 Microglial Polarization. Stroke, 48:2211-2221.

[111] Jiang M, Wang H, Jin M, Yang X, Ji H, Jiang Y, et al. (2018). Exosomes from MiR-30d-5p-ADSCs Reverse Acute Ischemic Stroke-Induced, Autophagy-Mediated Brain Injury by Promoting M2 Microglial/Macrophage Polarization. Cell Physiol Biochem, 47:864-878.

[112] Ransohoff RM (2016). A polarizing question: do M1 and M2 microglia exist? Nat Neurosci, 19:987-991.

[113] Deczkowska A, Keren-Shaul H, Weiner A, Colonna M, Schwartz M, Amit I (2018). Disease-Associated Microglia: A Universal Immune Sensor of Neurodegeneration. Cell, 173:1073-1081.

[114] Kobayashi K, Imagama S, Ohgomori T, Hirano K, Uchimura K, Sakamoto K, et al. (2013). Minocycline 
selectively inhibits M1 polarization of microglia. Cell Death Dis, 4:e525.

[115] Song D, Zhang X, Chen J, Liu X, Xue J, Zhang L, et al. (2019). Wnt canonical pathway activator TWS119 drives microglial anti-inflammatory activation and facilitates neurological recovery following experimental stroke. J Neuroinflammation, 16:256.

[116] Liu ZJ, Ran YY, Qie SY, Gong WJ, Gao FH, Ding ZT, et al. (2019). Melatonin protects against ischemic stroke by modulating microglia/macrophage polarization toward anti-inflammatory phenotype through STAT3 pathway. CNS Neurosci Ther, 25:1353-1362.

[117] Zhao R, Ying M, Gu S, Yin W, Li Y, Yuan H, et al. (2019). Cysteinyl Leukotriene Receptor 2 is Involved in Inflammation and Neuronal Damage by Mediating Microglia M1/M2 Polarization through NF- $\kappa \mathrm{B}$ Pathway. Neuroscience, 422:99-118.

[118] Tian X, Liu H, Xiang F, Xu L, Dong Z (2019). $\beta$ Caryophyllene protects against ischemic stroke by promoting polarization of microglia toward M2 phenotype via the TLR4 pathway. Life Sci, 237:116915.

[119] Li S, Lu X, Shao Q, Chen Z, Huang Q, Jiao Z, et al. (2019). Early Histone Deacetylase Inhibition Mitigates Ischemia/Reperfusion Brain Injury by Reducing Microglia Activation and Modulating Their Phenotype. Front Neurol, 10:893.

[120] Zhang H, Lu M, Zhang X, Kuai Y, Mei Y, Tan Q, et al. (2019). Isosteviol Sodium Protects against Ischemic Stroke by Modulating Microglia/Macrophage Polarization via Disruption of GAS5/miR-146a-5p sponge. Sci Rep, 9:12221.

[121] Yang S, Wang H, Yang Y, Wang R, Wang Y, Wu C, et al. (2019). Baicalein administered in the subacute phase ameliorates ischemia-reperfusion-induced brain injury by reducing neuroinflammation and neuronal damage. Biomed Pharmacother, 117:109102.

[122] Zhu J, Cao D, Guo C, Liu M, Tao Y, Zhou J, et al. (2019). Berberine Facilitates Angiogenesis Against Ischemic Stroke Through Modulating Microglial Polarization via AMPK Signaling. Cell Mol Neurobiol, 39:751-768.

[123] Chen C, Chu SF, Ai QD, Zhang Z, Guan FF, Wang SS, et al. (2019). CKLF1 Aggravates Focal Cerebral Ischemia Injury at Early Stage Partly by Modulating Microglia/Macrophage Toward M1 Polarization Through CCR4. Cell Mol Neurobiol, 39:651-669.

[124] Zheng Y, He R, Wang P, Shi Y, Zhao L, Liang J (2019). Exosomes from LPS-stimulated macrophages induce neuroprotection and functional improvement after ischemic stroke by modulating microglial polarization. Biomater Sci, 7:2037-2049.

[125] Chen F, Weng Z, Xia Q, Cao C, Leak RK, Han L, et al. (2019). Intracerebroventricular Delivery of Recombinant NAMPT Deters Inflammation and Protects Against Cerebral Ischemia. Transl Stroke Res, 10:719-728.

[126] He S, Liu R, Li B, Huang L, Fan W, Tembachako CR, et al. (2019). Propagermanium, a CCR2 inhibitor, attenuates cerebral ischemia/reperfusion injury through inhibiting inflammatory response induced by microglia. Neurochem Int, 125:99-110.

[127] Liu R, Liao XY, Pan MX, Tang JC, Chen SF, Zhang Y, et al. (2019). Glycine Exhibits Neuroprotective Effects in Ischemic Stroke in Rats through the Inhibition of M1 Microglial Polarization via the NF$\kappa \mathrm{B}$ p65/Hif-1 $\alpha$ Signaling Pathway. J Immunol, 202:1704-1714.

[128] Li F, Zhao H, Han Z, Wang R, Tao Z, Fan Z, et al. (2019). Xuesaitong May Protect Against Ischemic Stroke by Modulating Microglial Phenotypes and Inhibiting Neuronal Cell Apoptosis via the STAT3 Signaling Pathway. CNS Neurol Disord Drug Targets, 18:115-123.

[129] Gaire BP, Song MR, Choi JW (2018). Sphingosine 1phosphate receptor subtype $3(\mathrm{~S} 1 \mathrm{P})$ contributes to brain injury after transient focal cerebral ischemia via modulating microglial activation and their M1 polarization. J Neuroinflammation, 15:284.

[130] Li F, Ma Q, Zhao H, Wang R, Tao Z, Fan Z, et al. (2018). L-3-n-Butylphthalide reduces ischemic stroke injury and increases M2 microglial polarization. Metab Brain Dis, 33:1995-2003.

[131] Wang Q, Lv C, Sun Y, Han X, Wang S, Mao Z, et al. (2018). The Role of Alpha-Lipoic Acid in the Pathomechanism of Acute Ischemic Stroke. Cell Physiol Biochem, 48:42-53.

[132] Liu L, Liu X, Wang R, Yan F, Luo Y, Chandra A, et al. (2018). Mild focal hypothermia regulates the dynamic polarization of microglia after ischemic stroke in mice. Neurol Res, 40:508-515.

[133] Esposito E, Hayakawa K, Ahn BJ, Chan SJ, Xing C, Liang AC, et al. (2018). Effects of ischemic postconditioning on neuronal VEGF regulation and microglial polarization in a rat model of focal cerebral ischemia. J Neurochem, 146:160-172.

[134] Liu R, Diao J, He S, Li B, Fei Y, Li Y, et al. (2018). $\mathrm{XQ}-1 \mathrm{H}$ protects against ischemic stroke by regulating microglia polarization through PPAR $\gamma$ pathway in mice. Int Immunopharmacol, 57:72-81.

[135] Liu X, Wen S, Yan F, Liu K, Liu L, Wang L, et al. (2018). Salidroside provides neuroprotection by modulating microglial polarization after cerebral ischemia. J Neuroinflammation, 15:39.

[136] Xiang B, Xiao C, Shen T, Li X (2018). Antiinflammatory effects of anisalcohol on lipopolysaccharide-stimulated BV2 microglia via selective modulation of microglia polarization and down-regulation of NF- $\kappa \mathrm{B}$ p 65 and JNK activation. Mol Immunol, 95:39-46.

[137] Zhao H, Wan L, Chen Y, Zhang H, Xu Y, Qiu S (2018). FasL incapacitation alleviates CD4 T cellsinduced brain injury through remodeling of microglia polarization in mouse ischemic stroke. J Neuroimmunol, 318:36-44.

[138] Boddaert J, Bielen K, s Jongers B, Manocha E, Yperzeele L, Cras P, et al. (2018). CD8 signaling in microglia/macrophage M1 polarization in a rat model of cerebral ischemia. PloS one, 13:e0186937. 
[139] Ma L, Pan X, Zhou F, Liu K, Wang L (2018). Hyperforin protects against acute cerebral ischemic injury through inhibition of interleukin-17A-mediated microglial activation. Brain Res, 1678:254-261.

[140] Cheon SY, Kim EJ, Kim JM, Kam EH, Ko BW, Koo BN (2017). Regulation of Microglia and Macrophage Polarization via Apoptosis Signal-Regulating Kinase 1 Silencing after Ischemic/Hypoxic Injury. Front Mol Neurosci, 10:261.

[141] Wang R, Li J, Duan Y, Tao Z, Zhao H, Luo Y (2017). Effects of Erythropoietin on Gliogenesis during Cerebral Ischemic/Reperfusion Recovery in Adult Mice. Aging Dis, 8:410-419.

[142] Liu Z, Ran Y, Huang S, Wen S, Zhang W, Liu X, et al. (2017). Curcumin Protects against Ischemic Stroke by Titrating Microglia/Macrophage Polarization. Front Aging Neurosci, 9:233.

[143] Zhang M, Wu X, Xu Y, He M, Yang J, Li J, et al. (2017). The cystathionine $\beta$-synthase/hydrogen sulfide pathway contributes to microglia-mediated neuroinflammation following cerebral ischemia. Brain Behav Immun, 66:332-346.
[144] Wang Y, Huang Y, Xu Y, Ruan W, Wang H, Zhang $\mathrm{Y}$, et al. (2018). A Dual AMPK/Nrf2 Activator Reduces Brain Inflammation After Stroke by Enhancing Microglia M2 Polarization. Antioxid Redox Signal, 28:141-163.

[145] Espinosa-Garcia C, Sayeed I, Yousuf S, Atif F, Sergeeva EG, Neigh GN, et al. (2017). Stress primes microglial polarization after global ischemia: Therapeutic potential of progesterone. Brain Behav Immun, 66:177-192.

[146] Hawkins KE, DeMars KM, Alexander JC, de Leon LG, Pacheco SC, Graves C, et al. (2017). Targeting resolution of neuroinflammation after ischemic stroke with a lipoxin A analog: Protective mechanisms and long-term effects on neurological recovery. Brain Behav, 7:e00688.

[147] He Y, Ma X, Li D, Hao J (2017). Thiamet G mediates neuroprotection in experimental stroke by modulating microglia/macrophage polarization and inhibiting NF$\kappa \mathrm{B}$ p65 signaling. J Cereb Blood Flow Metab, 37:2938-2951. 